\title{
The Risk of Earty Rec urrent Venous Thromboembolism after Oral Anticoagulant Therapy in Patients with the G20210A Transition in the Prothrombin Gene
}

\author{
Sabine Eichinger, Erich Minar, Mirko Hirschl, Christine Bialonczyk, Milena Sta in, \\ Christine Mannhalter, Andreas Stümpflen, Ba rbara Sc hneider, Klaus Lechner, \\ Paul Alexander Kyrle
}

From the Departments of Intemal Medic ine I, Division of Hematology and Hemosta seology, a nd Intemal Medic ine II, Division of Angiology, Department of Medical Statistic s, University of Vienna, Hanusc hkra nkenhaus, Vienna, and Wilhelminenspital, Vienna, Austria

\section{Summary}

A G20210A transition in the prothrombin gene is a common risk factor of venous thrombosis. The risk of recurrent venous thromboembolism in carriers of the 20210A allele is unknown and guidelines for secondary thromboprophylaxis in these patients are not available.

In a prospective multicenter trial, 492 patients with a history of objectively documented venous thromboembolism were followed for a mean observation time of $24 \pm 16$ months after discontinuation of oral anticoagulants. Forty-two patients $(8.5 \%)$ were carriers of the $20210 \mathrm{~A}$ allele. Three of the 42 patients with the G20210A mutation (7\%) and 54 of 450 patients without the mutation (12\%) experienced recurrent venous thrombosis. At 24 months, the probability of recurrence was $8 \%$ (95\% CI 0-16.7) in patients with the mutation and was $12.2 \%$ (95\% CI 8.8-15.6) in patients without the mutation.

In conclusion, the risk of early recurrent venous thromboembolism is not higher in patients with the G20210A mutation than in those without the mutation. Therefore, long-term secondary thromboprophylaxis with oral anticoagulants in heterozygous carriers of the 20210A allele is not justified.

\section{Introduction}

A genetic variation in the 3'-untranslated region of the prothrombin gene, a $\mathrm{G}$ to A transition at nucleotide position 20210, confers an increased risk of venous thrombosis (1-3). The 20210 A allele has been observed in $5.5-7.1 \%$ of unselected consecutive caucasian patients with venous thromboembolism and in 1.2-2.3\% of healthy subjects (1-3). Compared to individuals with wildtype genotype, heterozygous carriers of the mutation have a 2.8- to 5-fold increased risk of venous thromboembolism (1-3).

The risk of recurrent venous thromboembolism is high shortly after the acute event and secondary thromboprophylaxis with oral anticoagulants is recommended for 6 months (4). Patients with cancer or the antiphospholipid antibody syndrome have an especially high risk of recurrence $(5,6)$ and are candidates for long-term anticoagulation. The same therapeutic principles apply to patients with congenital thrombo-

Correspondence to: Dr. Sabine Eichinger, Department of Internal Medicine I, Division of Hematology/Hemostaseology, Waehringer Guertel 18-20, A-1090 Vienna, Austria - Tel.: +43 140400 4410; FAX Number: +43 14026930 philia, such as a deficiency of antithrombin, protein $\mathrm{C}$, or protein $\mathrm{S}$, although - due to the low prevalence of these abnormalities - the benefit/risk ratio of long-term anticoagulant therapy has never been clearly established. In this respect, the risk of severe bleedings associated with long-term anticoagulation has to be taken into serious consideration. Conflicting data on the incidence of recurrence have been reported for patients with the factor V Leiden mutation (7-9) and prospective clinical trials to assess the optimal duration of secondary thromboprophylaxis in carriers of the mutation are warranted. Data on the risk of recurrent venous thromboembolism in patients with the G20210A mutation in the prothrombin gene are lacking and the optimal duration of oral anticoagulant therapy for these patients is unknown.

Since 1992, we prospectively followed patients with a history of venous thromboembolism and objectively documented all recurrent thromboembolic events which occurred following discontinuation of oral anticoagulant treatment. In the present analysis, we investigated whether carriers of the G20210A mutation in the prothrombin gene have an increased risk of recurrent venous thromboembolism.

\section{Methods}

Patients and Study Design

Details on patient enrollment and on the design of the Austrian Study of Recurrent Venous Thromboembolism (AUREC) have been previously reported (7). The study was conducted as a prospective multicenter trial. Patients had to fulfill the following criteria: age older than 18 years; objectively documented venous thromboembolism either by venography or color-coded duplex ultrasonography, or by perfusion/ventilation lung scan; treatment with oral anticoagulants for at least three months; and informed consent. Between July, 1992 and April, 1998, 905 consecutive patients were seen in four thrombosis centers. Two hundred and seventy-nine patients were excluded from the study because of deficiency of antithrombin, protein $\mathrm{C}$ or protein $\mathrm{S}$ (7 patients); systemic lupus erythematosus and/or an antiphospholipid antibody syndrome (10 patients); cancer ( 89 patients); or requirement of long-term anticoagulation (173 patients). All remaining 626 patients were screened for the presence of antithrombin-, protein C-, or protein S-deficiency, or antiphospholipid antibodies after discontinuation of oral anticoagulants. Twenty-three patients with either one of these defects were excluded from the study. Another 111 patients were unavailable for genetic testing.

The remaining 492 patients were seen at three-months intervals for the first 12 months and every six months thereafter. At study entry, patients were provided with written information on the symptoms of venous thromboembolism, and were instructed to report to one of the centers if symptoms of deep 
Table 1 Demographic and clinical characteristics of 492 patients with (+) and without (-) the G20210A mutation in the prothrombin gene and a history of venous thromboembolism (VTE)

\begin{tabular}{|c|c|c|c|}
\hline & $\begin{array}{c}+ \text { G20210A } \\
\text { no }(\%)\end{array}$ & $\begin{array}{c}- \text { G20210A } \\
\text { no }(\%)\end{array}$ & $p$-value \\
\hline Patients & $42(8.5)^{*}$ & $450(91.5)^{*}$ & \\
\hline $\operatorname{Sex}(M / F)$ & $18 / 24(43 / 57)$ & $209 / 241(46 / 54)$ & n.s. \\
\hline \multicolumn{4}{|l|}{ Age at first thrombotic event $(y r)$} \\
\hline mean $\pm S D$ & $41.6 \pm 14.4$ & $47 \pm 16.6$ & 0.02 \\
\hline median (range) & $39.5(17-73)$ & $47.4(14-86)$ & \\
\hline \multicolumn{4}{|l|}{ Site of thrombotic events } \\
\hline \multicolumn{4}{|l|}{ Venous thrombosis of the leg } \\
\hline proximal & $15(36)$ & $130(29)$ & n.s. \\
\hline distal & $11(26)$ & $157(35)$ & n.s. \\
\hline Axillary venous thrombosis & $1(2)$ & $18(4)$ & n.s. \\
\hline Pulmonary embolism & $15(36)$ & $145(32)$ & n.s. \\
\hline \multicolumn{4}{|l|}{ Triggering events } \\
\hline Spontaneous & $33(79)$ & $345(77)$ & n.s. \\
\hline Postoperative/posttraumatic & $9(21)$ & $105(23)$ & n.s. \\
\hline \multicolumn{4}{|l|}{ Number of VTE at study entry } \\
\hline first & $31(74)$ & $362(80)$ & n.s. \\
\hline recurrent & $\uparrow 1(26)$ & $89(20)$ & n.s. \\
\hline \multicolumn{4}{|l|}{ Duration of oral anticoagulant therapy } \\
\hline (mo) & $12 \pm 16$ & $8 \pm 13$ & n.s. \\
\hline mean $\pm S D$ & $6.5(3-84)$ & $6(3-168)$ & \\
\hline \multicolumn{4}{|l|}{ median (range) } \\
\hline \multicolumn{4}{|l|}{ Observation Time (mo) } \\
\hline mean $\pm \mathrm{SD}$ & $26 \pm 18$ & $25 \pm 18$ & n.s. \\
\hline median (range) & $23.5(0.6-51)$ & $22(0.5-88)$ & \\
\hline Factor $V$ Leiden & $8(19)$ & $135(30)$ & n.s. \\
\hline
\end{tabular}

* percent of total study population

vein thrombosis and/or pulmonary embolism occurred. Recurrent venous thromboembolism had to be confirmed by venography and/or a perfusion/ ventilation lung scan.

The study was approved by the local Ethics Committee, and written informed consent was obtained from all participants.

\section{Laboratory Analysis}

Genomic DNA was extracted from $3 \mathrm{ml}$ citrated blood according to standard procedures. $200 \mathrm{ng}$ DNA were amplified in $50 \mu \mathrm{l}$ reaction volumes containing $0.2 \mathrm{mmol} / \mathrm{l}$ of each desoxynucleotide triphosphate (dNTP), $10 \mathrm{mmol} / \mathrm{l} \mathrm{Tris-} \mathrm{HCl}$ ( $\mathrm{pH} 8.3$ at $25^{\circ} \mathrm{C}$ ), $50 \mathrm{mmol} / \mathrm{l} \mathrm{KCl}, 0.3 \mu \mathrm{mol} / \mathrm{l}$ of each primer [primer sequences were chosen according to Poort et al. (1)], $1.5 \mathrm{mmol} / \mathrm{l} \mathrm{MgCl}_{2}$ and one unit Ampli Taq Gold polymerase (Perkin Elmer Cetus, Norwalk, CT, USA). Amplifications were performed in a Thermal Cycler $480^{\circledR}$ (Perkin Elmer Cetus, Norwalk, CT, USA). An initial denaturation step of $10 \mathrm{~min}$ at $95^{\circ} \mathrm{C}$ was followed by 40 cycles of $1 \mathrm{~min}$ at $94^{\circ} \mathrm{C}, 1 \mathrm{~min}$ at $45^{\circ} \mathrm{C}$ and $1 \mathrm{~min}$ at $72^{\circ} \mathrm{C}$. A final extension step of $10 \mathrm{~min}$ at $72^{\circ} \mathrm{C}$ assured completion of the reaction. Aliquots of $7 \mu \mathrm{l}$ of each PCR product were submitted to digestion with 10 units Hind III in $1 \times$ Hind III buffer (Boehringer Mannheim, FRG) in a reaction volume of $30 \mu \mathrm{l}$. Following incubation for $90 \mathrm{~min}$ at $37^{\circ} \mathrm{C}$, the digests were analyzed by electrophoresis on $6 \%$ polyacrylamide gels.

Factor V Leiden was determined as described by Bertina et al. (10). Determination of antithrombin, protein $\mathrm{C}$ or protein $\mathrm{S}$ deficiency was performed as previously reported (11).

\section{Statistical Analysis}

Times to recurrence of venous thromboembolism (uncensored observations) or follow-up times in patients without recurrence (censored observations) were analyzed using survival time methods. The probability of recurrent venous thromboembolism was estimated following the method of Kaplan-Meier (12). To test for homogeneity between strata we applied the log-rank and the generalized Wilcoxon test. Categorial data were checked for homogeneity using contingency table analyses ( $\chi^{2}$-test). Simple descriptive statistics were computed to provide a clear presentation of the data. For numerical operations a SAS software package was used.

\section{Results}

\section{Patient Characteristics}

Of the 492 patients, $42(8.5 \%)$ were carriers of the G20210A mutation in the prothrombin gene (Table 1). One of these patients was homozygous for the 20210A allele. Patients with and without the G20210A transition did not differ with regard to distribution of gender, site of thrombosis, triggering events, number of previous thromboses, duration of previous oral anticoagulant therapy, or observation time. Patients with the prothrombin mutation were younger at the time of their first venous thrombotic event than patients without the mutation. The mean $( \pm$ SD) age at study entry was $44.4( \pm 14)$ years in carriers of the $20210 \mathrm{~A}$ allele and was $50.3( \pm 16.5)$ in those with the wildtype genotype $(p=0.02)$. The majority of the patients experienced spontaneous venous thromboembolism. Factor V Leiden was present in $19 \%$ of the patients with the mutation and in $30 \%$ of the patients without the mutation $(\mathrm{p}=0.1)$.

In 5 patients with and in 70 patients without the mutation the study was terminated because of pregnancy ( 1 with and 2 without the mutation), because the patient was lost for follow-up (1 with and 34 without the mutation), because of diagnoses of cancer (3 without the mutation) or because antithrombotic treatment for reasons other than venous thrombosis had to be administered ( 3 patients with and 31 without the mutation). These patients were withdrawn from the study and were censored at the time of withdrawal.

\section{Recurrent Venous Thromboembolism}

Three (7\%) of 42 patients with the G20210A transition and 54 (12\%) of 450 patients without the mutation had recurrent venous thromboembolism. The cumulative probability of recurrence did not differ

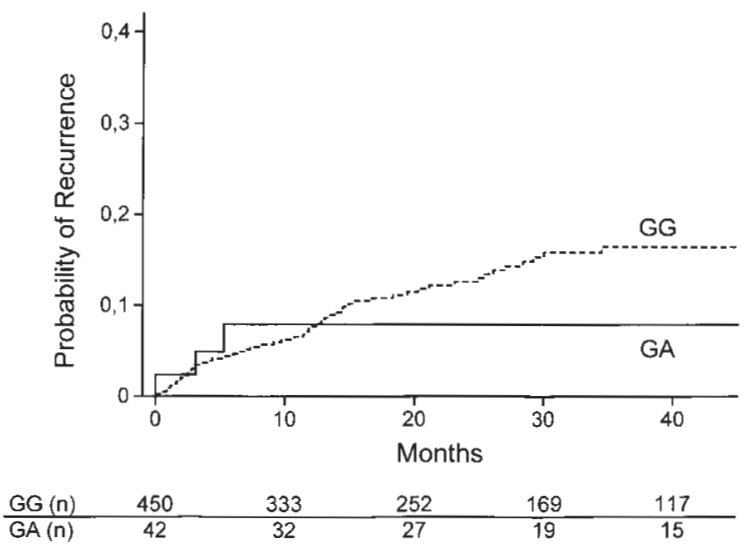

Fig. 1 Cumulative probability of early recurrent venous thromboembolism in patients with (GA) and without (GG) the G20210A mutation in the prothrombin gene 
between patients with and without the G20210A mutation (Wilcoxon $\mathrm{p}=0.4$, log-rank $\mathrm{p}=0.3$ ) (Fig. 1). At 24 months, the probability of recurrence was $8 \%(95 \% \mathrm{CI} 0-16.7)$ in patients with the mutation and was $12.2 \%$ (95\% CI 8.8-15.6) in patients without the mutation.

The relative risk (RR) of recurrent venous thromboembolism was $0.6(95 \%$ CI $0.2-1.8, p=0.3)$ in patients with the G20210A transition. After adjustment for age and factor V Leiden carrier status, the RR was $0.7(95 \%$ CI $0.2-2.1 ; \mathrm{p}=0.5)$.

Two (5\%) patients with the G20210A mutation and $32(7 \%)$ patients without the mutation developed deep vein thrombosis. Pulmonary embolism occurred in $1(4 \%)$ patient with the prothrombin mutation and in $2(5 \%)$ patients without the mutation.

In a subset of patients with a single spontaneous venous thrombosis 3 of $24(12.5 \%)$ patients with the mutation and 29 of $268(10.8 \%)$ without the mutation had recurrent venous thrombosis. In these patients, the probability of recurrence at 24 months was $10.3 \%$ (95\% CI 6-14) and $13.6 \%$ (95\% CI 0-28), respectively (Wilcoxon $p=0.7$, log-rank $p=0.9)$.

\section{Disc ussion}

The prevalence $(8.5 \%)$ of the G20210A mutation in our cohort of consecutive, prospectively followed patients with a history of a venous thromboembolism was similar to that found in Dutch (6.2\%), Swedish (7.1\%), and British (5.5\%) thrombosis patients (1-3). Together with the factor V Leiden mutation (R506Q), which causes resistance of factor V to activated protein $\mathrm{C}(10)$, the G20210A mutation is one of the most common genetic risk factors of venous thrombosis.

After an acute venous thromboembolic event, it is common practice to treat patients with oral anticoagulants for a period of six months (4). Long-term secondary thromboprophylaxis is generally recommended in patients with an increased risk of recurrence, such as cancer, the antiphospholipid antibody syndrome or antithrombin-deficiency $(5,6)$. The benefit of oral anticoagulants has to be carefully weighed against their risks. For instance, in a large study by Palaretti et al. the annual risk of major or fatal bleedings was $1.1 \%$ and $0.25 \%$, respectively (13). In carriers of the $\mathrm{G} 20210 \mathrm{~A}$ mutation, the risk of recurrent venous thromboembolism is currently unknown, and guidelines for secondary thromboprophylaxis are not available.

Our data clearly indicate that the risk of recurrent venous thromboembolism within the first two years after discontinuation of oral anticoagulants is not higher in patients with the G20210A mutation than in those without the mutation. Within this period of time, $8 \%$ of the patients with the prothrombin mutation compared to $12 \%$ without the mutation had recurrent thrombotic disease. From these data, extended secondary thromboprophylaxis with oral anticoagulants does not seem indicated in patients heterozygous for the G20210A mutation in the prothrombin gene.

Although the majority of our patients was treated with oral anticoagulants for 3-6 months after their thrombotic event, some patients received secondary thromboprophylaxis for a longer period of time. This may have affected the overall recurrence rate of our study cohort and may have attenuated a potential difference between the two patient groups.

The mean observation time of our study cohort was approximately two years and we can therefore only comment on the risk of early rather than late recurrence. It could well be the case that patients with the G20210A transition in the prothrombin gene have an increased risk of recurrence when followed for a much longer period of time. To prevent late recurrent thrombotic events, long-term administration of anticoagulants is necessary. Considering that the bleeding risk of oral anticoagulants is directly related to the duration of therapy (13), it is unlikely that long-term anticoagulant therapy is beneficial in heterozygous carriers of the prothrombin mutation.

There is evidence that the co-existence of risk factors potentiates the risk of thrombosis (14-16). To eliminate a potential inhomogeneity in our patient population with regard to other permanent risk factors, patients with antithrombin-, protein C-, or protein S-deficiency, patients with cancer or the antiphospholipid antibody syndrome were not included. Factor V Leiden was unknown when our trial was started. To exclude a possible effect of the factor V Leiden mutation on the risk of recurrence, we calculated the probability of recurrence for patients with and without the G20210A mutation who were not carriers of factor V Leiden. After exclusion from the Kaplan-Meier analysis of the patients with factor $\mathrm{V}$ Leiden, the probability of recurrent thrombosis was unchanged in both patient groups (data not shown). Furthermore, following adjustment for factor $\mathrm{V}$ Leiden carrier status the relative risk remained unaffected compared to the previous analysis. As we have previously shown, the presence of the factor $\mathrm{V}$ Leiden mutation also does not confer a higher risk of recurrence in our patient population (7).

There is evidence that the risk of recurrent venous thromboembolism is lower in patients with transient risk factors (i.e. trauma or surgery) and that patients with recurrent venous thrombosis have an increased risk of recurrence $(4,5)$. The proportion of patients with transient risk factors or recurrent venous thrombosis was approximately $25 \%$ and was equally distributed in patients with and without the mutation. To evaluate the influence of the two subgroups of patients on our analysis, we excluded all patients with transient risk factors or previous recurrence. In the Kaplan-Meier analysis, the probability of recurrence in patients with the G20210A mutation was not significantly different from those without the mutation. Because of the small number of patients these data have to be interpreted with caution.

In conclusion, the risk of early recurrent venous thromboembolism is not higher in heterozygous carriers of the G20210A mutation than in patients without the mutation. Therefore, extended secondary thromboprophylaxis with oral anticoagulants does not seem to be justified in patients heterozygous for the G20210A mutation in the prothrombin gene. The risk of recurrence, however, may be increased in homozygous carriers of the 20210A allele as well as in heterozygous carriers with other co-existing permanent risk factors of venous thrombosis. In these patients, the recurrence rate and the optimal duration of secondary thromboprophylaxis remain to be investigated.

\section{Acknowledgements}

We are grateful to Dr. Paolo Prandoni (University Hospital of Padua, Padua, Italy) for critically reviewing the manuscript. The study was supported by the Jubiläumsfonds of the Oesterreichische Nationalbank (\# 6410).

\section{References}

1. Poort SR, Rosendaal FR, Reitsma PH, Bertina RM. A common genetic variation in the 3'-untranslated region of the prothrombin gene is associated with elevated plasma prothrombin levels and an increase in venous thrombosis. Blood 1996; 88: 3698-703.

2. Hillarp A, Zöller B, Svensson PJ, Dahlbäck B. The 20210 A allele of the prothrombin gene is a common risk factor among Swedish outpatients with verified deep venous thrombosis. Thromb Haemost 1997; 78: 990-2.

3. Cumming AM, Keeny S, Salden A, Bhavnani M, Shwe M, Shwe KH, Hay CRM. The prothrombin gene G20210A variant: prevalence in a U.K. anti- 
coagulant clinic population. Brit J Haematol 1997; 98: 353-5.

4. Schulman S, Rhedin A-S, Lindmarker P, Carlsson A, Lärfars G, Nicol P, Loogna E, Svensson E, Ljungberg B, Walter H, Viering S, Nordlander S, Leijd B, Jönsson K-Å, Hjorth M, Linder O, Boberg J, and the Duration of Anticoagulation Trial Study Group. Comparison of six weeks with six months of oral anticoagulant therapy after a first episode of venous thromboembolism. N Engl J Med 1995; 332: 1661-5.

5. Prandoni P, Lensing AWA, Cogo A, Cuppini S, Villalta S, Carta M, Cattelan A, Polistena P, Bernardi E, Prins MH. The long-term clinical course of acute deep venous thrombosis. Ann Intern Med 1996; 125: 1-7.

6. Khamashta MA, Cuadrado MJ, Mujic F, Taub NA, Hunt BJ, Hughes GRV. The management of thrombosis in the antiphospholipid-antibody syndrome. N Engl J Med 1995; 332: 993-7.

7. Eichinger S, Pabinger I, Stümpflen A, Hirschl M, Bialonczyk C, Schneider B, Mannhalter C, Minar E, Lechner K, Kyrle PA. The risk of recurrent venous thromboembolism in patients with and without factor $\mathrm{V}$ Leiden. Thromb Haemost 1997; 77: 624-8.

8. Simioni P, Prandoni P, Lensing AWA, Scudeller A, Sardella C, Prins MH, Villalta S, Dazzi F, Girolami A. The risk of recurrent venous thromboembolism in patients with an Arg509 $\rightarrow$ Gin mutation in the gene for factor V (factor V Leiden). N Engl J Med 1997; 336: 399-403.

9. Ridker PM, Miletich JP, Stampfer MJ, Goldhaber SZ, Lindpaintner K, Hennekens CH. Factor V Leiden and risks of recurrent idiopathic venous thromboembolism. Circulation 1995; 92: 2800-2.

10. Bertina RM, Koeleman BPC, Koster T, Rosendaal FR, Dirven RJ, de Ronde H, van der Velden PA, Reitsma PH. Mutation in blood coagulation factor V associated with resistance to activated protein C. Nature 1994; 369 :
$64-7$.

11. Pabinger I, Brücker S, Kyrle PA, Schneider B, Korninger HC, Niessner H, Lechner K. Hereditary deficiency of antithrombin III, protein C, and protein $\mathrm{S}$ : prevalence in patients with a history of venous thrombosis and criteria for rational patient screening. Blood Coagul Fibrinolysis 1992; 3: 547-53.

12. Kaplan EL, Meier P. Nonparametric estimation from incomplete observations. J Am Stat Assoc 1958; 53: 457-81.

13. Palaretti G, Leali N, Coccheri S, Poggi M, Manotti C, d'Angelo A, Pengo V, Erba N, Moia M, Ciavarella N, Devoto G, Berettini M, Musolesi S, on behalf of the Italian Study on Complications of Oral Anticoagulant Therapy. Bleeding complications of oral anticoagulant treatment: an inception-cohort, prospective collaborative study (ISCOAT). Lancet 1996; 348: 423-8.

14. Zöller B, Berntsdotter A, Garcia de Frutos P, Dahlbäck B. Resistance to activated protein $\mathrm{C}$ as an additional genetic risk factor in hereditary deficiency of protein S. Blood 1995; 85: 3518-23.

15. Koeleman BP, Reitsma PH, Allart CF, Bertina RM. Activated protein C resistance as an additional risk factor for thrombosis in protein C-deficient families. Blood 1994; 84: 1031-5.

16. van Boven HH, Reitsma PH, Rosendaal FR, Baiston TA, Chowdhury V, Bauer KA, Scharrer I, Conard J, Lane DA. Factor V Leiden (FV R506Q) in families with inherited antithrombin deficiency. Thromb Haemost 1996; 75: 417-21. 